\section{International Scientific Journal Theoretical \& Applied Science}

p-ISSN: 2308-4944 (print)

e-ISSN: 2409-0085 (online)

Year: 2015

Issue: 06

Volume: 26

Published: $30.06 .2015 \quad$ http://T-Science.org
Kseniia Kovalenko

MSc. Information Technology and Innovation Management,

Graduate School of Management,

St.Petersburg State University

Ksenia-kov@ya.ru

SECTION 24. Sociological research.

\title{
E-AUCTION PLATFORMS IN RUSSIA: THE ISSUES OF POLITICS AND COUNTRY-OF-ORIGIN
}

\begin{abstract}
The focus of the current research is on online auction platforms in Russia as one of the major ecommerce realms continuing to grow worldwide. Although extensive previous research in the field of online auctions provides a comprehensive theoretical background, no research has yet been conducted regarding the Russian user's decision to participate in online auctions taking into account political factors and county of origin, COO, effects, thus leading to a specific knowledge gap. Subsequently, this discussion is focused on empirical results that address and can be used not only by the general online auction community of buyers and sellers but also by online auction platform operators to strengthen their positions in the Russian market.

Key words: online auctions, country-of-origin effect, Russian market, e-commerce, consumer behavior.

Language: English

Citation: Kovalenko K (2015) E-AUCTION PLATFORMS IN RUSSIA: THE ISSUES OF POLITICS AND COUNTRY-OF-ORIGIN. ISJ Theoretical \& Applied Science 06 (26): 66-70.

Soi: http://s-o-i.org/1.1/TAS*06(26)15 Doi: crossef http://dx.doi.org/10.15863/TAS.2015.06.26.15
\end{abstract}

\section{Introduction}

Online auctions, perceived as one of the most promising areas in terms of multisided-platform development, make it possible to dismiss demographic and temporal barriers and allow the purchase of products anytime from anywhere in the world. The emerging phenomenon of e-auctions affects industrial dynamics, creates new forms of competition, reveals new forms of collaborative innovation across firms and poses a host of new fundamental questions. The online auction marketplace segment faces competition from traditional department, warehouse, boutique, discount and general-merchandise stores in addition to online retailers and their related mobile offerings, online and offline classified services, and other shopping channels such as offline and online home shopping networks [1]. Though there is no doubt that e-commerce is rising globally nowadays, the pace of adoption and use of different e-commerce marketplaces varies significantly across different countries. For instance, eBay is considered to be one of the major players in the global online auction market since it was the first one to launch Internetbased online auction platform. However, the extent to which eBay is used among users from different countries varies dramatically. According to
Alexa.com, the leading position belongs to the eBay platform in the United States with $54,80 \%$ of total visitors (rank in the country - 7). Then comes South Korea with $5,10 \%$ of total visitors (rank in the country - 7) and Russia with 3,3\% of total eBay visitors (rank in the country - 24). This is further refined when the countries' market size is taken into account, minimizing misinterpretation of the actual market position. On this basis, the Alexa statistics on the estimated unique visitors in the eBay case reveal that the top five positions are allocated among the US, UK, Canada, Germany and France respectively. Thus, the questions become: why is Russia still far away from other countries? What do Russian users prefer: foreign or local e-platforms? Do politics and/or county-of-origin of e-platforms matter?

\section{Online auctions in Russia}

More than 20 million people in Russia shop online [2] and the most popular goods for Russians are electronics, household items and fashion [3]. Considering the current state of the Russian online auction market, saturation is still far away. In addition, although it is possible to find around ten local online auctions platforms (Table 1), only one of them - Molotok.ru - has real market power, by trying to build its model as an analogue to eBay in the Russian market. 
Online auctions in Russian market, 2014.

\begin{tabular}{|l|l|l|l|l|}
\hline \multicolumn{1}{|c|}{ Site URL } & \multicolumn{1}{c|}{ Introduced } & \multicolumn{1}{c|}{ Categories } & \multicolumn{1}{c|}{ Status } \\
\hline Molotok.ru & molotok.ru & 1999 & All & Active \\
\hline Meshok.ru & meshok.ru & 1999 & All & Active \\
\hline Antikwariat.ru & www.antikwariat.ru & 2010 & Collectibles \& Antiques & Active \\
\hline 24au.ru & 24au.ru & 2008 & All & Active \\
\hline GreedyBidder & www.greedybidder.com & 2012 & All & N/A \\
\hline eTorg & www.etorg.com & 2005 & All & Active \\
\hline Torge & www.torge.ru & 2003 & Collectibles \& Antiques & N/A \\
\hline
\end{tabular}

The online auction segment seems to be a promising field in terms of future growth and development in Russia, but requires that platform operators overcome the barrier of low credibility of online transactions in order to truly make the online auction market more attractive for Russian customers.

Rapid growth of the e-commerce market in Russia suggests that this area needs extensive and systematic research. Online-auction buying and selling patterns in Russia have not been studied to the extent that other areas of the Internet have been investigated. Indeed, most of the information regarding online auction platforms in Russia can be found only in social media without any systematic approach and/or theoretical background. Moreover, none of the previous research has been focused on the role of political issues or country of origin effects in regards to online auction platforms. In contrast to this, the country-of-origin concept should be integrated into studies on online auctions, so that the connection between confidence in foreign and Russian e-stores and willingness to participate in online auctions is properly analyzed.

\section{Data collection}

The primary data required for the study have been collected from respondents from different Russian cities to make the sample more representative of the entire population. The cities involved in the survey have been Saint Petersburg, Moscow, Ufa, Viborg, Stavropol, etc. The sample size of 225 has been taken from among the urban population of over 14 years of age. 12 questions related to the use of e-commerce services, e-payment systems and online auctions were asked in a dichotomous form and with the use of a rating scale from 0 to 10 . The questions covered such aspects as satisfaction over the current state of e-commerce development in Russia, knowledge about different ecommerce forms, attitude towards online auctions and behavior patterns [4].

\section{Influence of political realities}

The deterioration of Russian-Ukrainian relations due to the crisis in recent years (2014-2015), coupled with the "war of sanctions" between the EU, US and
Russia have resulted in the emergence of a number of business risks, so that several companies have already announced that they are abandoning their Russian operations due to the impact of the crisis. One of the biggest threats for foreign online platforms is the money-transfer sanctions program imposed on Russian banks by the US and the EU. For example, although eBay-owned PayPal was legally registered in Russia as a provider of financial services, money transfers are nonetheless facing problems arising from sanctions.

Money-transfer transactions are undermined in a similar manner as those already affecting US credit card organizations Visa and MasterCard as the issuance of credit cards and the individual limits for cardholders are tied to the accounts of Russian blacklisted banks. Uncertainty related to online payments as a consequence of certain political movements can thus affect users' willingness to conduct any kind of operation online.

Supporting the online payment concerns, it is relevant to mention that Russian users do not want to buy or sell any kind of goods online in the case that only online payments are available (Figure-1). The "strength" of the preference was measured with the use of a zero-to-ten scale and then regrouped into three categories representing "strong" (0-3), "medium" (4-6) and "low" (7-10) influence. A strong preference towards paying in cash upon the order receipt makes it tricky for foreign companies to navigate in the Russian market of e-commerce.

Moreover, according to the survey conducted within the scope of this research, the political situation really does influence Russian users' decisions to buy or sell items in certain e-stores or from certain vendors (in case of $\mathrm{C} 2 \mathrm{C}$ online platforms) (Figure-2). The majority of respondents have indicated that, even though they are aware of current challenges, they do not base their decisions on political moves. However, around 44\% ("medium" plus "strong" groups) of respondents mentioned that they can change their decision in terms of entering and carrying out any kind of ecommerce activities because of a certain perception of the political situation. 


\section{Unwillingness to buy/sell online in case only online payment is possible}

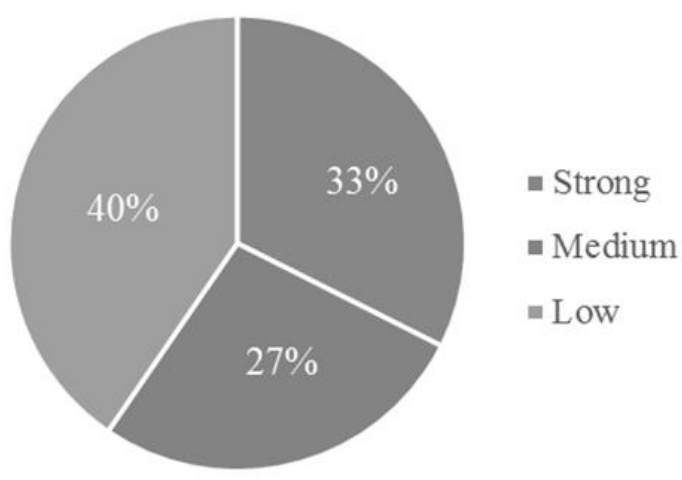

Figure 1 - Russian users' avoidance of online payment.

Influence of political situation over the decision to buy/sell online in the certain e-stores

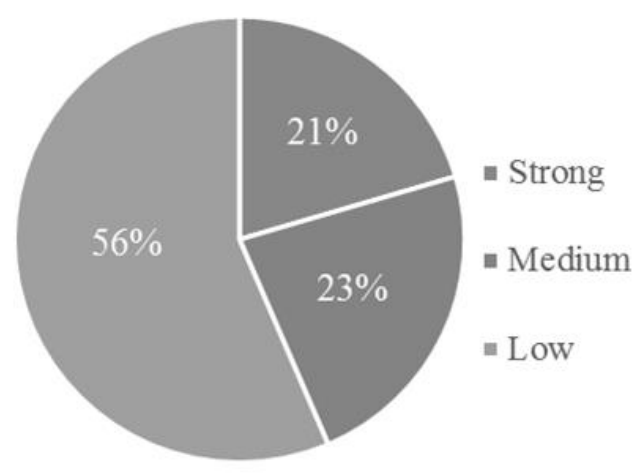

Figure 2 - Impact of political situation over Russian users' decision.

A connection can be made with $\mathrm{COO}$ effect theories, raising up questions about what contributes to Russian users' confidence towards Russian or foreign online stores and platforms.

\section{Theoretical background on country-of-origin (COO) effects}

Research on country-of-origin (COO) effects has emerged as an important area of investigation in consumer behavior and consumer decision-making in online and offline commerce [5, 6]. Despite the fact that findings about the influence of country-of-origin on product evaluation and purchasing decision differ in nature, the common element is that consumers base their evaluation on the product or service itself [7]. In most cases, consumers use $\mathrm{COO}$ cues as a cognitive shortcut in the case of limited information about the particular item. However, previous studies in various fields have also shown that consumers may not always be affected by $\mathrm{COO}$ cues in the same way [8]. First, focus is put on the simplification of information processing and the use of $\mathrm{COO}$ as a quality indicator. Nicole Koschate-Fischer (2012) empirically supported the view that the COO cue influences not only consumers' perceptions but also their actions: users tend to spend more money for a branded product from a $\mathrm{COO}$ with a more favorable country image [9]. Second, the phenomenon of COO is used for marketing purposes as the current business environment is characterized by intensified competition on a global scale among firms from various countries and the extensive use of media. $\mathrm{Hu}$ and Wang (2010) examined the online auction setting (eBay) in their study to examine whether consumers are willing to pay different prices for a given product depending on the origin of the retailer. The findings revealed that US retailers are able to command a premium, which "appears to stem from country-oforigin equity instead of trading risk or product quality" [10]. In the context of the Russian market, those findings can be especially valuable as there are two main online auction platforms in the market: eBay and Molotok, that are American and Russian 
respectively. In addition, there is growing interest in the other foreign online $\mathrm{C} 2 \mathrm{C}$ platforms managed by Alibaba Group, which are from China. Following $\mathrm{Hu}$ and Wang's research, the origin of the online auction platform is the focus of the current analysis, with the derived conclusion providing complementary insights into country of origin effects concerning online auctions. Therefore, the following hypotheses were proposed:

H1: Russian users, who are confident in a Russian estore/vendor, are more likely to take part in online auctions

H2: Russian users, who are confident in a foreign estore/vendor, are more likely to take part in online auctions.

\section{Confidence in Foreign vs. Russian e-stores}

Understanding the Russian users' willingness to participate in online auctions can be crucial not only for auctioneers but also for the buyers and sellers themselves. Until now, the focus has mostly been put on the cognitive-behavior component of a consumer's attitude, not relying much on the affective side due to the problems associated with measurement. The attitude towards different online auctions varies depending on the country of origin. The aim of this research is to analyze whether the willingness to participate in online auctions is connected to confidence in Russian or foreign e- store/vendors. A chi-square test was conducted with the help of SPSS 22 to test the hypotheses that were stated earlier in the study.

H1: Russian users, who are confident in a Russian estore/vendor are more likely to take part in online auctions

The null hypothesis proposes that the willingness to participate in online auctions (i.e., n/a, yes, no) is independent of users' confidence levels in a given Russian e-store/vendor (i.e., n/a, very weak, weak, neutral, strong, very strong). The analysis yielded a $\mathrm{X}^{2}$ statistics of 7,956 and p-value 0,633 , that makes it impossible to reject the null hypothesis. The result implied that Russian users who are confident in Russian e-stores do not differ significantly in whether or not they would like to participate in online auctions.

H2: Russian users, who are confident in a foreign estore/vendor, are more likely to take part in online auctions

The chi-square test results revealed a $\mathrm{X}^{2}$ statistics of 31,319 and p-value 0,001 , so that the null hypothesis was rejected. As a result, it can be stated that Russian users with a high level of confidence in foreign online stores or sellers are either willing or not willing to participate (or their answer is $\mathrm{n} / \mathrm{a}$ ) in online auctions.

Cross tabulation results.

Table 2

\section{Crosstab}

\begin{tabular}{|ll|r|r|r|r|}
\hline \multirow{2}{*}{ Count } & \multicolumn{2}{|c|}{ Willingness to participate in online auction } & \multirow{2}{*}{ Total } \\
\cline { 3 - 6 } & & $\mathrm{n} / \mathrm{a}$ & \multicolumn{1}{|c|}{ No } & \multicolumn{1}{|c|}{ Yes } & 33 \\
Confidence in foreign & $\mathrm{n} / \mathrm{a}$ & 9 & 12 & 12 & 51 \\
online stores \& vendors & Neutral & 23 & 6 & 22 & 37 \\
& Strong & 13 & 2 & 22 & 24 \\
& Very strong & 6 & 0 & 18 & 37 \\
& Very weak & 13 & 10 & 14 & 43 \\
& Weak & 21 & 9 & 13 & 225 \\
\hline
\end{tabular}

Hypothesis testing results with the use of chi-square analysis.

Table 3

\begin{tabular}{|l|l|c|c|c|}
\hline \multicolumn{1}{|c|}{ Research hypothesis } & \multicolumn{1}{|c|}{ Statistical null hypothesis } & $\mathbf{X}^{2}$-statistics & P-value & Conclusion \\
\hline $\begin{array}{l}\text { Hl: Russian users, who are } \\
\text { confident in Russian e- } \\
\text { store/vendor are more likely to } \\
\text { take part in online auctions }\end{array}$ & $\begin{array}{l}\text { Willingness to participate in online } \\
\text { auctions is independent of } \\
\text { confidence in Russian e-store/vendor }\end{array}$ & 7,956 & 0,633 & $\begin{array}{c}\text { Not reject } \\
\text { null }\end{array}$ \\
$\begin{array}{l}\text { H2: Russian users, who are } \\
\text { confident in foreign e- } \\
\text { store/vendor are more likely to } \\
\text { take part in online auctions }\end{array}$ & $\begin{array}{l}\text { Willingness to participate in online } \\
\text { auctions is independent of } \\
\text { confidence in Foreign e- } \\
\text { store/vendor }\end{array}$ & 31,319 & 0,001 & Reject null \\
\hline \hline
\end{tabular}

ISPC Education \& Innovation, 
The conclusion is supported with the crosstabulation data provided above (Table 2). The majority of users who are confident in foreign online stores have shown a desire to participate in online auctions. The findings provoke the idea that the country of origin of the e-auction/vendor really matters in terms of Russian users' willingness to enter and act in online auctions (Table 3).

\section{Discussion and conclusion}

As the concern about the importance of country of origin effects was raised in the theoretical overview and market analysis, an investigation on the dependence between the willingness to participate and level of confidence in Russian and foreign e-stores was carried out to expand on this. The willingness to participate in online auctions is independent from the level of confidence in Russian e-stores/vendors; however, it is connected with the confidence level in foreign e-stores.

Coupled with uncertain macroeconomic conditions in Russia, the COO effect could play a pivotal role in making a particular e-platform more or less attractive for users. The link between confidence in foreign e-stores/vendors due to the affective component of attitude and the willingness to participate in an online auction was found to be statistically significant.

Thus, although a causal link is not necessarily clear, a strong correlation is at least present, justifying an additional effort in terms of the communication strategy of a particular online auction. Referring to one of the most recent studies of Koschate-Fisch [8], if the firm (online auction platform in this case) finds itself in the fortunate position of benefiting from a favorable COO image, it should emphasize the notion of $\mathrm{COO}$ in its communication strategy by, for example, calling attention to the $\mathrm{COO}$ in advertising activities and executing the digital marketing strategy mentioned before. Though there are no guarantees of short-term results, consumers should notice and process the $\mathrm{COO}$ as an informational cue in at least a medium or long-run context, thereby enhancing their willingness to participate and pay in online transactions.

\section{References:}

1. (2014) Market Line. E-commerce in Russia.

2. Morgan Stanley (2013) Russian eCommerce. Industry View In-line. Morgan Stanley Research.

3. (2013) Data Insight. Ecommerce in Russia.

4. Yi-Chun, Huang, Wu Yen-Chun Jim, Wang, and Boulanger (2011) "Decision making in online auctions." Management Decision 49, no. 5: 784-800. Inspec.

5. Brodowsky, Glen, Justin Tan, and Ofer Meilich (2004) "Managing country-of-origin choices: competitive advantages and opportunities." International Business Review 13, no. 6: 729748.

6. Sila, Ismail (2013) "Factors affecting the adoption of B2B e-commerce technologies." Electronic Commerce Research 13, no. 2: 199236.

7. Lee and Wei-Na (2009) "Country-of-Origin Effects on Consumer Product Evaluation and Purchase Intention: The Role of Objective
Versus Subjective Knowledge." Journal of International Consumer Marketing 21, no. 2: 137-151.

8. Yu-Min, Wang, Yeh Ching-Hsuan, Wang YiShun, and Xie Min-Quan (2013) "The relationships among presentation mode, product type, consumers' product knowledge, and consumers' purchase intention in the ecommerce environment." Inspec.

9. Koschate-Fischer, Nicole, Adamantios Diamantopoulos, and Katharina Oldenkotte (2012) "Are Consumers Really Willing to Pay More for a Favorable Country Image? A Study of Country-of-Origin Effects on Willingness to Pay." Journal Of International Marketing 20, no. 1: 19-41.

10. $\mathrm{Hu}$ and Wang (2010) "Country-of-Origin Premiums for Retailers in International Trades: Evidence from eBay's International Markets." Journal of Retailing 86: 200-207. 